\title{
Psychosocial stress, standing time and overweight are risk factors for pregnancy induced hypertension: A case control study N Perera ${ }^{1}$, C Abeysena ${ }^{2}$
}

\section{Abstract \\ Objective :}

To determine the risk factors for pregnancy induced hypertension (PIH).

\section{Methods :}

This was a case control study, carried out at Castle Street Hospital for Women during August to September 2006. Hundred mothers newly diagnosed as having PIH were chosen as cases and 100 mothers with uncomplicated pregnancies as controls. Both cases and controls had a period of amenorrhoea of $>20$ weeks. Psychosocial stress was measured using General Health Questionnaire 30 (GHQ) and the Modified Life Event Inventory (MLEI). Maternal socio-demographic information and other data were collected using an interviewer administered questionnaire and a record sheet. Multivariate logistic regression analysis was applied to control for confounders and the results were expressed as odds ratios (OR) and $95 \%$ confidence intervals $(95 \% \mathrm{CI})$.

\section{Results :}

After adjusting for confounding effect experience of ${ }^{3} 2$ life events during pregnancy (OR:2.1, 95\%CI:1.06-10.9), a maternal BMI of ${ }^{3} 25 \mathrm{~kg} / \mathrm{m}^{2}$ (OR:2.4, 95\%CI:1.1-5.0), maternal age of ${ }^{3} 28$ years (OR:3.9, 95\%C.I:2.0-7.5), history of ante partum haemorrhage (OR:3.4, 95\%CI:1.1-10.9) and standing for $>1.5$ hours at one stretch (OR:3.4, 95\%CI:1.67.4) had statistically significant associations with developing PIH.

\section{Conclusions :}

Psychosocial stress during pregnancy, being an overweight or obese women, age ${ }^{32} 28$ years, history of antepartum haemorrhage and standing ${ }^{3} 1.5$ hours at one stretch were risk factors for PIH.

Key words case control study; hypertension; life change events; pregnancy; risk factors; stress

\section{Introduction}

Hypertensive disorders are the most common complication experienced by pregnant mothers through out the world. Its incidence varies from $6 \%$ to $8 \%$ of all pregnancies. ${ }^{1}$ Pregnancy induced hypertension (PIH) is a clinical syndrome characterized by the development of hypertension after 20 weeks period of amenorrhea. PIH could be associated with proteinurea (pre-eclampsia) or without proteinurea. Incidence of PIH was $4.1 \%$ in United States (USA) ${ }^{2}, 1.4 \%$ Taiwan ${ }^{2}$ and $2.8 \%$ in Canada. $^{3}$

PIH is one of the leading causes for maternal and neonatal morbidity and mortality. ${ }^{4}$ Mothers will experience a spectrum of complications such as cerebral haemorrhages, hepatic lesions leading to jaundice and liver failure, also renal lesions, placental abruption and lastly maternal death ${ }^{4}$ according to the severity of the PIH. When considering maternal deaths, hypertensive disorders accounts for $17.6 \%$ and $46 \%$ in USA and United Kingdom ${ }^{5}$ respectively. Neonatal complications such as preterm delivery, growth retardation and foetal death are common among PIH mothers. ${ }^{4} \mathrm{PIH}$ is also accounts for $65 \%$ of the foetal deaths in United Kingdom. ${ }^{5}$

Many studies have reported that psychosocial stress is a risk factor for $\mathrm{PIH}^{2,3,6}$ Psychosocial stress has been measured using different methods. The most commonly used instrument is the Modified Life Events Inventory, which assesses the number of stressful events experienced ${ }^{2,7}$ during pregnancy. The General Health Questionnaire has been used in some studies $^{7}$ to measure psychological distress experienced during pregnancy. Also several other risk factors have been identified to be having association with PIH such as socio demographic factors like maternal $\mathrm{age}^{7-9}$, level of maternal education $^{10,11 .}$, social class $^{11}$ and employment during pregnancy. ${ }^{7,11}$ With the recent socio demographic changes, people of higher social classes adopt more sedentary life style. Also with the increased consumption of high fat diet and lack of exercise had caused obesity in population. Studies conducted in Malaysia $^{12}$ USA $^{13}$ and Israel ${ }^{14}$ had reported that pre pregnancy body mass index (BMI) more than $25 \mathrm{~kg} /$ $\mathrm{m}^{2}$ was a risk factor for PIH. Some of the other described risk factors are primiparity ${ }^{7,10,11,15}$, previous history of pre-eclampsia ${ }^{7,8,15,16}$ and family history of pre-eclampsia. ${ }^{8,17}$ However, the effect of psychosocial stress, social class and level of maternal education on PIH had shown controversial findings. ${ }^{2,6,15}$

1. Registrar in Community Medicine, Department of Public Health, Faculty of Medicine, University of Kelaniya, Ragama,

2. Senior Lecturer, Department of Public Health, Faculty of Medicine, University of Kelaniya, Ragama, 
Further identifying such risk factors at booking visit is helpful so that close follow up of high risk mothers will help to identify PIH at initial stages before developing complications. This is a very cost effective strategy to reduce maternal morbidity as follow up of mothers with risk factors can be done with using a sphygmomanometer which is available at any primary care level medical institution. No studies have been conducted in Sri Lanka to determining the risk factors for PIH. Therefore the objective of the study was to determine the risk factors for PIH while paying emphasis on psychosocial stress and socio demographic factors.

\section{Methods}

A cases control study was conducted at Castle Street Hospital for Women in Colombo from August 2006 to September 2006. PIH was defined as systolic blood pressure of $140 \mathrm{mmHg}$ or more or a diastolic blood pressure of $90 \mathrm{mmHg}$ or more, taken by two readings at least four hours apart. One hundred newly diagnosed $\mathrm{PIH}$ women at more than 20 weeks of gestation were recruited from the antenatal clinics. One hundred controls were chosen from the women who attended the same antenatal clinics with an uncomplicated pregnancy with their systolic blood pressure below $140 \mathrm{mmHg}$ and diastolic blood pressure below $90 \mathrm{mmHg}$ and without proteinurea. Controls were women having the next registration number to a case who fulfil the criteria for controls. Women with heart disease, diabetes, epilepsy, twin pregnancy were excluded from both cases and control groups.

Pre tested four study instruments were used for the study. The first instrument was an interviewer administered questionnaire which gathered information on socio demographic data and details of current and past pregnancies. The second was also an interviewer administered questionnaire which included "Modified Life Event Inventory" (MLEI). The third instrument was the General Health Questionnaire-30 (GHQ) which was a self administered questionnaire. Both the MLEI and GHQ measured the psychosocial stress. The fourth instrument was a record sheet which used to obtain information on current and past obstetric history from the mother's pregnancy record card issued by the obstetric unit and pregnancy record card issued by the village antenatal clinic. The data collection was done by principal investigator in a confidential setting after obtaining informed written consent from the women. Ethical clearance was obtained from the Ethical Review Committee of the Faculty of Medicine, University of Kelaniya.

Data analysis was performed by using SPSS windows $16^{\text {th }}$ version. After entering the data it was rechecked to see the accuracy of data. Statistical analysis included bivariate logistic regression, which was carried out to determine the odds ratio (OR) for PIH in terms of each of the socio-demographic and maternal variables and for psychosocial stress. Cutoff values with regard to the height was determined by using the Receiver Operator
Characteristic curves in order to obtain a more accurate estimate of the association and cut off values for pre pregnancy weight, and time of standing were taken according to their median. Unconditional multiple logistic regression was carried out to control the confounding factors. Eligibility for including the variables into the regression model was based on both statistical basis ( $p$-value $<0.25$ ) as well as biological plausibility ${ }^{18}$. The initial model contained all variables and it was modified by concurrent addition and deletion of variables until the most suitable model was accomplished. ${ }^{18}$

\section{Results}

Mean age of the study population was 27 years with a standard deviation of 3.9 years. Majority $73.5 \%$ (147) were between 20-29 years of age followed by the age groups $30-40$ years and 18-19 years with the percentages $24.4 \%$ (48) and $2.5 \%$ (5) respectively. Of the study population $48.5 \%$ (97) were primiparous, $51.5 \%$ (103) multiparous and $91.5 \%$ (183) Sinhalese. Majority 52\% (104) of the women were educated up to grade 6-10.

Experience of $\geq 2$ life events during pregnancy, GHQ score of $>5$, exposure to passive smoking, standing $>1.5$ hours at the stretch, pre pregnancy BMI $\geq 25 \mathrm{~kg} / \mathrm{m}^{2}$, age $>28$ years, history of antepartum haemorrhage, family history of PIH, past history of $\mathrm{PIH}$, and previous miscarriage were found to be significantly associated with PIH in the bivariate analysis (Table 1). In multivariate analysis, experience of $\geq 2$ life events during pregnancy, standing $>1.5$ hours at the stretch, pre pregnancy $\mathrm{BMI} \geq 25$ $\mathrm{kg} / \mathrm{m}^{2}$, age $>28$ years, history of antepartum haemorrhage, were found to be significantly associated with PIH (Table 2). 
Table 1 Unadjusted odds ratios for exposure variables and PIH

\begin{tabular}{|c|c|c|c|c|c|}
\hline Exposure variables & $\begin{array}{c}\text { Cases } \\
(n=100)\end{array}$ & $\begin{array}{c}\text { Controls } \\
(n=100)\end{array}$ & $\begin{array}{l}\text { Odds } \\
\text { Ratio }\end{array}$ & $95 \% \mathrm{CI}$ & $P$ value \\
\hline Experience of $\geq 2$ life events & 43 & 26 & 2.15 & $1.18-3.9$ & 0.01 \\
\hline GHQ score $>5$ & 15 & 6 & 2.76 & $1.18-3.90$ & 0.04 \\
\hline Age $\geq 28$ years & 61 & 28 & 4.02 & $2.2-7.3$ & $<0.001$ \\
\hline Educational level grade $\leq \mathbf{1 0}$ & 56 & 53 & 1.13 & $0.65-1.97$ & 0.67 \\
\hline Employment during pregnancy & 31 & 24 & 1.42 & $0.76-2.65$ & 0.27 \\
\hline Lower social class & 41 & 44 & 0.88 & $0.50-1.55$ & 0.67 \\
\hline $\begin{array}{l}\text { Per capita monthly income } \leq \\
\text { 5000 SLRs }\end{array}$ & 56 & 52 & 1.17 & $0.67-2.05$ & 0.57 \\
\hline Pre pregnancy height $\geq 153 \mathrm{~cm}$ & 42 & 50 & 0.72 & $0.41-1.26$ & 0.26 \\
\hline Pre pregnancy weight $\geq 56 \mathrm{Kg}$ & 56 & 48 & 1.37 & $0.79-2.41$ & 0.26 \\
\hline $\mathrm{BMI} \geq 25 \mathrm{Kg} / \mathrm{m}^{2}$ & 36 & 18 & 2.56 & $1.33-4.96$ & 0.004 \\
\hline Primiparous & 50 & 47 & 1.13 & $0.65-1.96$ & 0.67 \\
\hline $\begin{array}{l}\text { History of antepartum hemor- } \\
\text { rhage }\end{array}$ & 18 & 5 & 4.17 & $1.48-11.73$ & 0.004 \\
\hline Previous miscarriage & 18 & 8 & 2.52 & $1.04-6.18$ & 0.03 \\
\hline Past history of PIH & 17 & 3 & 8.56 & $2.33-31.62$ & 0.001 \\
\hline Family history of PIH & 21 & 6 & 4.21 & $1.61-10.97$ & 0.002 \\
\hline Exposure to passive smoking & 26 & 14 & 2.16 & $1.05-4.43$ & 0.03 \\
\hline $\begin{array}{l}\text { Standing } \geq 1.5 \text { hours at the } \\
\text { streach }\end{array}$ & 36 & 15 & 3.19 & $1.61-6.32$ & 0.001 \\
\hline Sleeping $\leq 8$ hours. & 60 & 65 & 0.81 & $0.45-1.43$ & 0.46 \\
\hline
\end{tabular}




\begin{tabular}{llllcc}
\hline \multicolumn{1}{c}{ Exposure variables } & $\begin{array}{c}\text { Regression } \\
\text { coefficient }\end{array}$ & $\begin{array}{c}\text { Standard } \\
\text { error }\end{array}$ & $\begin{array}{c}\text { Odds ra- } \\
\text { tio }\end{array}$ & \multicolumn{2}{c}{ 95\%CI value } \\
\hline Experience of $\geq 2$ life events & 0.72 & 0.35 & 2.06 & $1.06-10.87$ & 0.04 \\
GHQ score $>5$ & 1.12 & 0.58 & 3.04 & $0.98-9.55$ & 0.054 \\
& & & & & \\
Standing $\geq 1.5$ hours at the stretch & 1.23 & 0.40 & 3.43 & $1.59-7.39$ & 0.002 \\
Age $\geq 28$ years & 1.36 & 0.34 & 3.88 & $2.01-7.49$ & 0.001 \\
History of antepartum haemorrhage & 1.22 & 0.60 & 3.36 & $1.05-10.87$ & 0.049 \\
BMI $\geq 25 \mathrm{~kg} / \mathrm{m}^{2}$ & 0.86 & 0.38 & 2.37 & $1.12-5.00$ & 0.023 \\
\end{tabular}

Discussion

From this study it was evident that women who experienced $\geq 2$ life events during pregnancy was a risk factor for PIH. Further psychological distress measured by GHQ score of $>5$ was not significantly associated with $\mathrm{PIH}$ in multivariate analysis, however the $\mathrm{P}$ value was 0.054 . Three studies ${ }^{2,3,6}$ had also reported that psychosocial work stress during pregnancy was significantly associated with PIH. All above studies ${ }^{2,3,6}$ considered the stress caused by job. In the present study, psychosocial stress was assessed by two methods. Experiences of life events indicate stressful conditions in the past where as GHQ measure the psychosocial during the past two weeks.

Standing $>1.5$ hours at a stretch was a risk factor for PIH. Our finding was consistent with the finding of one other study ${ }^{19}$ which showed that standing $>2.5$ hours per day during first or second or both trimesters was a risk factor for maternal complications including PIH. Further the above study ${ }^{19}$ also reported that high energy expenditure during the second trimester was a risk factor for maternal complications. In the present study sleeping $\leq 8$ hours per day was not significantly associated with PIH. It was consistent with the results of a study ${ }^{20}$ reported that less sleeping hours per day was not associated with adverse maternal outcomes including $\mathrm{PIH}$ in any of the trimesters.

We found that overweight and obese women had high risk of developing PIH. This study supported previous findings ${ }^{7,19,21}$ that body mass index of $>25 \mathrm{Kg} / \mathrm{m}^{2}$ was a risk factor for PIH. However, social class was not a risk factor for developing $\mathrm{PIH}$ and it was consistent with the study reported by Lawlor. ${ }^{22}$ In contrast to our findings Mireles $^{11}$ had reported that high social class was a risk factor for PIH. Mireles ${ }^{11}$ categorised the social class according to place where the delivery of the child took place (private hospital/ public hospital), where as in the current study social class was based on British Social Class Classification.

In the current study low maternal education (less than 10 years of schooling) was not associated with PIH. Our finding was consistent with the study reported by Lee ${ }^{7}$, yet other two studies contradicted our finding. ${ }^{7,10}$ The latter two studies ${ }^{7,10}$ defined educated up to grade five as low educational level. Our sample size was not enough to analysed data considering cut off as up to primary educational level.

According to current study being employed during pregnancy was not associated with $\mathrm{PIH}$. This was consistent with the result reported by Funai ${ }^{10}$ but two other studies ${ }^{7,11}$ showed contradictory results. Proportion of working females among 20-40 year age group in Sri Lanka amounts to $47 \%{ }^{23}$ In the current study it was $31 \%$ and $24 \%$ for cases and controls respectively. The fact that not having a significant association could be due to 'employed during pregnancy' was defined to be working throughout pregnancy in the current study where as women who had worked more than three months during pregnancy had been considered as employed during pregnancy in the study reported by Mireles. $^{11}$

We found that women's age of $>28$ years was a risk factor for PIH. This finding supports the findings of three previous studies that advanced maternal age was a risk factor for PIH.

When considering the limitations of this study it was conducted at a government hospital. Women who were followed up at private hospitals might differ in socio-demographic characteristics where they might show a different association with PIH. Further it might compromise the generalisability of the findings. As a case control study recall bias is inevitable. Further women who were chosen as controls might have a possibility of developing PIH in the course of their pregnancy. Ideally controls should have been followed up to their delivery and should exclude mothers who develop PIH.

In conclusion psychosocial stress during pregnancy, maternal age $\geq 28$ years, being a overweight or obese woman, history of antepartum hemorrhage in current pregnancy and standing for $>1.5$ hours during pregnancy at a stretch were risk factors for PIH 


\section{References}

1. Norwitz Errol R, Julian N, Robinson, John T. Prevention of pre-eclampsia: Is it possible? Clinical obstetric and Gynecology. 1999; 42: 436-454.

2 Landsbergis PA, Hatch M. Psychosocial work stress and pregnancy induced hypertension. Epidemiology; 1996; 7: 346 - 351 .

3 Marcoux S, Berube S, Brison C, Monder M. Job strain and pregnancy induced hypertension. Epidemiology. 1999; 7: 376-382.

4. Geoffrey VP. Obstetrics by ten teachers. 16th ed. 1995. p100 -110.

5. Fiona M, Redman C, Walker J, Baker P. The preeclampsia community guide line. BMJ. 2005; 330: $576-580$.

6. Klonoff C, Hillary S, Jilie L, Piper FC. Job stress and preeclampsia. Epidemiology. 1996; 3: 245 249.

7. Lee CJ, Hsieh TT, Chiu K, Chen C, Lo LM, Hung TH. Risk factors for pre-eclampsia for Asian population. International journal for Gynecology and Obstetrics. 2000; 2: 327-333.

8. Duckitt K, Harrington D. Risk factors for preeclampsia : systematic review of controlled studies. B.M.J. 2005; 330,: 565-567.

9. Gabrele M, Roman H, Robpillard PY, Julian C, Kauffman E. Biol report. Gynaecol. 2004; 33(7): 615-7.

10 Funai EF, Paltiel OB, Malaspina D, Friedlander Y, Deutsch L. Risk factors for pre-eclampsia in nulliparous and parous women. Peadiatric perinatal Epidemiol. 2005; 1: 59-68.

11. Mireles PC, Harlow SD, Carrilio CI, Nunenz RM. Risk factors for pre-eclampsia among working women in Mexico city. Paediatric and perinatal epidemiology. 2001; 15: 40-46.

12. Adinegara LA, Razzk MS. Does life style increase the incidence of pregnancy induced hypertension. Med J Malaysia. 2004; 59 (1): 39-44.

13. Bodnar LM, Ness RB, Markovic, Robert JM. Risk of pre-eclampsia rises with increased prepregnancy BMI. Ann Epidermol. 2005;15(7): 475-82 .

14. Erezweiss I, Erez O, Shoham M, Vandi I, Holcberg D, Mazor M. The association between maternal obesity, glucose intolerance and hypertensive disorders in pregnancy in non diabetic mothers. Hypertens pregnancy. 2005; 24(2):125-36.

15. Anorlu RI, Namdi C, Iwula G, Odum CU. Risk factors for preeclampsia in Lagos. Australian and New Zealand Journal of Obstetrics and Gynecology. 2005; 45: 278-282.

16. Lie RT, Rasmussen S, Brunborg H, Gjessing HK, Lie NE, Irgens LM. Foetal and maternal contribution to risk factors in preeclampsia. AmJOG. 1998; 165: 1343 - 1347.

17. Nilson E, Helena SR, Sven C, Lichtenstein P. The importance of genetic and enviormental effect for preeclampsia and gestational hypertension. International journal of Gynecology and Obstetrics.

1997; 111: $200-206$.
18. Medical Statistics Unit, 2003. Report on Indoor mobidity and mortality statistics. Colombo.

19. Abeysena C, Jayawardana P, Seneviratne R. Effect of energy expenditure on pregnancy outcome: A cohort study. Journal of College of Community Physicians of Sri Lanka. 2008; 13 (2): 1-8.

20. Abyesena $C$. The effect of physical activity and psychosocial strss of pregnancy outcome. MD Thesis. Community Medicine. Post Graduate Institute of Medicine. Colombo.; 2002.

21. Kassam M, Michele A, Godfrey B, Woelk JW, Sarah M, Longstaff L, Sorensen TK. Risk factors for preeclampsia among Zimbabwean women. Paediatric and perinatal Epidemiology .1998; 12: 253 - 262 .

22. Lawlor DA, Morton SM, Nitsch D, Leon DA. Association between childhood and adulthood socioeconomic position and pregnancy induced hypertension, results from the Aberdeen children of the 1950s cohort study. J Epidermol Community health. 2005; 59(1): 49-55.

23. Censes and Statistics Department. Report on Census and Statistics; 2000. 